
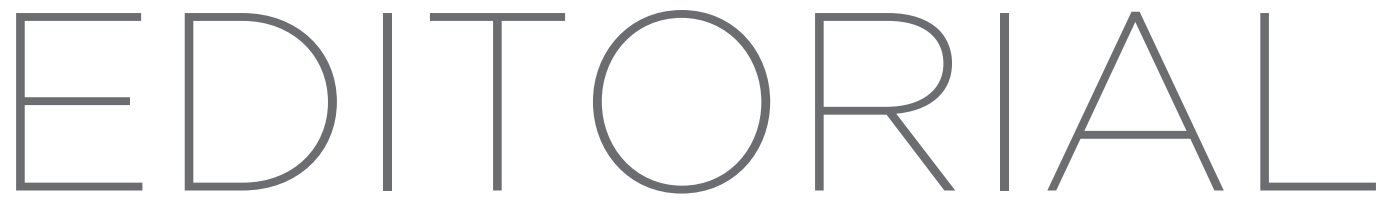

http://dx.doi.org/10.18222/eae.v26i63.3749

\section{TENDÊNCIAS DA AVALIAÇÃO DA APRENDIZAGEM EM SALA DE AULA}

A revista Estudos em Avaliação Educacional, em seu número 63, apresenta como Tema em Destaque um conjunto de artigos que abordam diversos aspectos relativos à avaliação da aprendizagem em sala de aula.

Apesar de apresentar-se como um tema de grande relevância no que se refere ao cotidiano dos docentes no interior dos estabelecimentos de ensino, sejam eles da educação básica ou da educação superior, constata-se que, comparativamente às produções acadêmicas brasileiras direcionadas às análises das políticas de avaliação em larga escala, notadamente nas três últimas décadas, a avaliação da aprendizagem aparece como uma temática de pesquisa pouco explorada. Esse movimento se reflete, inclusive, nos artigos submetidos a esta revista, cujo fluxo de textos sobre a temática se mostra incipiente.

Não obstante, quando se lança mão das estatísticas de acesso aos artigos geradas pelo Sistema Eletrônico de Editoração de Revistas (SEER), implantado no periódico no ano de 2014, é possível observar que muitos dos textos mais acessados e com maior número de downloads abordam aspectos da avaliação da aprendizagem em sala de aula, sendo um número expressivo deles publicado há mais de uma década.

Considerando as duas tendências: (1) a da centralidade da avaliação em larga escala na produção acadêmica nacional nas últimas três décadas no campo da avaliação educacional e consequente presença maciça nos artigos publicados pelo EAE; e (2) a da predominância dos acessos e downloads de artigos sobre avaliação da aprendizagem em sala de aula, 
pode-se, à primeira vista, identificar certo descompasso entre a produção acadêmica brasileira publicada na revista e as demandas relativas ao campo da avaliação educacional.

Uma das hipóteses apresentadas pelo corpo editorial do EAE em relação a essa circunstância seria a de que os acessos e downloads desses artigos, em grande parte das vezes, foram realizados por docentes que não necessariamente estão vinculados às instituições de pesquisa. Os textos procurados, nesse caso, atenderiam mais a uma demanda de formação de professores que buscam uma melhor compreensão do papel da avaliação da aprendizagem em âmbito escolar, como também um aprimoramento de suas práticas avaliativas.

Isso posto, entende-se que a missão da revista vai além da divulgação das produções científicas nacionais e internacionais no campo da avaliação educacional. Ela possui também um papel importante na disseminação de artigos voltados à formação inicial e permanente dos docentes e de demais membros das equipes escolares, provendo-os para uma melhor atuação nas suas práticas cotidianas.

No intuito de cada vez mais promover a articulação dessa dupla missão do EAE, este número traz, na seção Tema em Destaque, um conjunto de artigos relativos à avaliação da aprendizagem em sala de aula, abarcando seus diferentes aspectos. Eles abordam o conceito de avaliação e sua interface com ensino, aprendizagem e currículo; as percepções e práticas de avaliação de professores e de estudantes no ensino superior; os sentidos dos abusos de poder provenientes de práticas avaliativas equivocadas; bem como uma reflexão substancial a respeito da avaliação da aprendizagem de línguas materna e estrangeira considerando a nova base epistemológica digital e as novas demandas sociais.

Também estão disponíveis nesta edição artigos que apresentam propostas específicas de avaliação da aprendizagem, como a avaliação visual dirigida aos alunos surdos no ensino médio, assim como os instrumentos construídos para avaliar práticas dos alunos de graduação em Enfermagem no decorrer do estágio em Cuidados Intensivos e Enfermagem em Emergência. Além disso, dois outros estudos trazem contribuições relevantes para o aprimoramento das 
práticas avaliativas no interior dos estabelecimentos de ensino, sendo que um deles propõe o uso de portfólio como um instrumento de avaliação no ensino de Ciências e o outro apresenta o conselho de classe como instrumento de avaliação formativa da aprendizagem.

Há, por fim, na seção Outros Temas, um artigo sobre as contribuições da autoavaliação docente no sistema de avaliação de desempenho docente em Portugal e outro que propõe uma reflexão importante quanto ao aprimoramento das questões utilizadas nas avaliações oficiais dirigidas aos alunos da educação básica, especificamente no que se refere à planificação de figuras geométricas tridimensionais.

Boa leitura a todos.

Nelson Gimenes

Editor Coordenador 
